\title{
Juan Bautista Cassani Vivaldo. Un hombre de negocios genovés representante diplomático de los Cantones Esguízaros en el Madrid de Carlos II
}

\author{
Mercedes Gómez Oreña ${ }^{1}$
}

Resumen. La defensa de los territorios obligará a la Monarquía Hispánica a la contratación continuada de regimientos en los cantones suizos, lo que fomentará las relaciones bilaterales. Los enviados cantonales jugarán un papel fundamental en este entramado diplomático. Esta investigación se ha centrado en la labor desarrollada, durante la segunda mitad del siglo XVII, por el embajador suizo en la corte española, Juan Bautista Cassani Vivaldo, un hombre de negocios genovés con importantes relaciones clientelares dentro de la élite política.

Palabras clave: monarquía hispánica; cantones suizos; diplomacia; reclutamiento; siglo XVII.

\section{[en] Juan Bautista Cassani Vivaldo. A Genoese Businessman as Diplomatic Agent of the Swiss Cantons in the Madrid of Carlos II}

\begin{abstract}
The defence of their territories will force the Hispanic Monarchy to a continued recruitment of regiments from the Swiss Cantons, which will encourage their bilateral relationships. The cantonal envoys will play an essential role in the diplomatic networks. This research has focused on the task carried out in the Spanish court, during the second half of seventeenth century, by the Swiss ambassador Juan Bautista Cassani Vivaldo, a Genoese businessman with important contacts inside the political elite.
\end{abstract}

Keywords: Spanish Monarchy; Swiss Cantons; diplomacy; recruitment; 17th century.

Sumario. 1. Juan Bautista Cassani Vivaldo. 2. Antecedentes de la embajada en época de Juan Bautista Cassani. 3. La legación diplomática. 4. Las negociaciones diplomáticas. 5. Epílogo.

Cómo citar: Gómez Oreña, M. (2017) Juan Bautista Cassani Vivaldo. Un hombre de negocios genovés representante diplomático de los Cantones Esguízaros en el Madrid de Carlos II, en Cuadernos de Historia Moderna 42.1, 87-106. 
Ubicados geográficamente en el llamado Camino español ${ }^{2}$-que unía los territorios de la Monarquía Hispánica de Italia y Flandes-, los Cantones Suizos eran fuente de suministro de efectivos militares para las guerras europeas y ocupaban un lugar privilegiado dentro del entramado de las relaciones internacionales por estar rodeados de territorios pertenecientes a las tres principales naciones de la época: el Imperio, Francia y España. El enfrentamiento casi constante entre las dos últimas posibilitó que los soldados suizos estuvieran permanentemente integrados en las huestes francesas, lo que facilitó un acercamiento mayor de los suizos hacia esta corona, obligando con ello a la española a hacer frecuentes contrataciones de tropas, dándoles una categoría mayor de la que tenían estos territorios. Aunque esta importancia se irá desvaneciendo a la vez que decaiga su fama en el campo de batalla ${ }^{3}$.

Contrariamente a lo que cabría esperarse por el papel que jugaron en el contexto bélico europeo y particularmente en los ejércitos hispánicos, la historiografía de nuestro país no ha mostrado un interés especial por ellos, a pesar del trabajo pionero de Quer i Boule sobre las embajadas extraordinarias de Saavedra Fajardo ${ }^{4}$, literato y diplomático con un gran sentido político y gran conocedor de la Helvética ${ }^{5}$. Por el contrario, en Francia e Inglaterra los mercenarios suizos han tenido una mayor notoriedad ${ }^{6}$. Por ello este trabajo se centrará en las conexiones existentes entre los Cantones Católicos y la Monarquía española a través de la gestión de su embajador en la corte, Juan Bautista Cassani Vivaldo, un hombre de negocios genovés establecido en Madrid en la segunda mitad del siglo XVII.

Existían tres caminos para llegar a Flandes desde el Milanesado: el del oeste, que atravesaba Saboya; el central, que cruza los Cantones Suizos, y el del este, que pasaba por la Valtelina, territorio confederado con estos últimos. Sobre estas rutas Parker, G.: El ejército de Flandes y el Camino Español (1567-1659), Madrid, Alianza Editorial, 1985 y Rodríguez Hernández, A. J.: España, Flandes y la Guerra de Devolución (16671668) Guerra, reclutamiento y movilización para el mantenimiento de los Países Bajos Españoles, Madrid, Ministerio de Defensa, Secretaria General Técnica, 2007.

3 A pesar de la disminución de los efectivos militares suizos en los ejércitos extranjeros, todavía en el siglo XVII se calcula que servían no menos de 50.000 hombres cada año. Sobre los regimientos empleados por la Corona Española véase MAFFI, D.: La cittadella en armi. Esercito, società e finanza nella Lombardía di Carlo II. 16601700, Milano, Franco Angeli, 2010; "«Fieles y leales vasallos del rey». Soldados italianos en los ejércitos de los Austrias Hispánicos en el siglo XVII”, Comisión Internacional de Historia Militar, 94, (2016), pp. 21-39; García Hernán, E. Y MafFi, D.: Guerra y sociedad en la Monarquía Hispánica: política, estrategia y cultura en la Europa Moderna, 1500-1700, Madrid, Ediciones del Laberinto, 2016; Codignola, L.: "Le relazioni tra Genova e la Svizzera in antico regime, 1563-1806", en Bosshart-Pfluger, C. (ed.): Genova crocevia tra Svizzera e Italia. Il Consolato Generale di Svizzera a Genova 1799-1999, Frauenfeld, Stuttgart, Wien, Verlag Huber, 2000, pp. 37-51.

4 Quer I Boule, L.: La Embajada de Saavedra Fajardo en Suiza. Apuntes Históricos, (1639-1642), Madrid, Imprenta de Ramona Velasco, 1931. Sobre Saavedra Fajardo véase también Aldea VAQUero, Q.: España y Europa: correspondencia de Saavedra Fajardo, Madrid, Consejo Superior de Investigaciones Científicas, Real Academia de la Historia, 2008, Guillamón Álvarez, J.: "El barroco y 'Las Empresas' de Saavedra Fajardo", Monteagudo: Revista de literatura española hispanoamericana y teoría de la literatura, 86, (1984), pp. 95-100.

5 Bolzern, R.: "España y Suiza en la época de la Paz de Westfalia", en 350 años de la Paz de Westfalia, Madrid, Biblioteca Nacional de España y Fundación Carlos de Amberes, 1999, pp. 63-71. Este autor señala a Saavedra Fajardo como el español mejor conocedor de los suizos.

6 Entre otros autores podemos citar a McCormach, J.: One Million Mercenaries. Swiis sordiers in the armies of the world, London, Leo Cooper, 1993; Convisier, A.: Histoire Militaire de la France, Paris, Presses Universitaires de France, t. 1, 1992, y СнаGniot. J.: Guerre et société à l'époque moderne, Paris, Presses Universitaires de France, 2001. 


\section{Juan Bautista Cassani Vivaldo}

Los orígenes de este personaje se sitúan en la ciudad de Taggia, diócesis de Albenga y dominio de la Serenísima República de Génova. Desconocemos la fecha exacta de su nacimiento, aunque podemos estimar su alumbramiento entre finales de los años veinte y principios de los treinta del siglo XVII. Fue uno de los cinco hijos del matrimonio formado por Juan María Cassani y Benedicta Vivaldo, naturales de las ciudades de Génova y Taggia, respectivamente. La escasez de datos proporcionados por las fuentes españolas nos impide conocer la estirpe de los Cassani, aun así los primeros apuntes de ésta se sitúan en la segunda mitad del siglo XVIII, superando en más de un siglo los de nuestra investigación, si bien se los señala como una ilustre familia originaria de Milán con casa solariega en Génova ${ }^{7}$. Por el contrario, las referencias de los Vivaldo son más prolíficas, puesto que se asentaron en España durante el reinado de los Reyes Católicos, cuando la necesidad de numerario de su hacienda atrajo a la península a los grandes financieros genoveses: los Imperial, Centurión, Gentil, Lomelín, Doria, Espínola, Piquinoti, Pallavicino, entre otros ${ }^{8}$. Según Rivarola y Pineda, los Vivaldo pertenecían a un linaje noble y patricio, ejerciendo como tal dentro del gobierno de la República de Génova, donde desempeñaron los más altos cargos ${ }^{9}$. Su abolengo venía de antiguo, puesto que este mismo autor señala a Pedro Vivaldi -los familiares utilizarán indistintamente el apellido Vivaldo o Vivaldi- como miembro de este clan, haciendo referencia de su existencia en 1310, de hecho, su hija Violante casará en 1385 con Nicolás III de Rivarola, cabeza y pariente mayor de toda la cuna de su apellido y señor del castillo de Rivarola ${ }^{10}$.

En la familia Vivaldo encontramos dos ramas, los naturales de Taggia y los de Génova. En la genealogía aportada para la obtención del hábito de la Orden de Santiago de Juan Esteban Vivaldo Canevaro, primo carnal de Juan Bautista Cassani, tramitada en el año 1649 , no quedó determinada cual era la procedencia originaria ${ }^{11}$. Los testigos no se pusieron de acuerdo en quiénes eran los ascendientes, lo que sí afirmaron fue que, a pesar de no estar inscritos en los libros de nobleza, en esa estimación se les tenía por ser una familia muy antigua que cumplía los requisitos necesarios. El Senado de la República de Génova también lo juzgó así, es más, el Consejo de Cientos, junto al Dux y los dos Colegios de Senadores y Procuradores propusieron en el año 1626 que Jerónimo Vivaldo fuera inscrito en el libro de la

Las primeras referencias se remontan a José Antonio Casani y Giraldeli, V Conde romano de Giraldeli, VI barón de Lardies y mayordomo de semana de su majestad. Nació en Milán el 4 de julio de 1763 y casó con la condesa doña María de Cron. El escudo de armas aparece señalado con el número 710, siendo su fondo en azur con tres fajas de oro y en el jefe un creciente de plata, García CARrafFa, A. y A.: Diccionario Heráldico y Genealógico de Apellidos Españoles y Americanos, Salamanca y Madrid, vol. LXXIII (corregido LXXV), 1949, pp. 72-78.

8 Herrero Sánchez, M. y Álvarez-Ossorio Alvariño, A.: "La aristocracia genovesa al servicio de la Monarquía Católica: el caso del III marqués de Los Balbases (1630-1699)”, en Herrero SÁnchez, M., Ben YesSEF Garfia, Y. R., Bitossi, C. y Puncuh, D. (coord.): Génova y la Monarquía Hispánica (1528-1713), Génova, Atti della Società Ligure di Storia Patria, Nuova Serie, vol. LI (CXXV), fasc. I, 2011, pp. 331-366.

9 Agustín Vivaldo aparece señalado como Dux de Génova en 1559, mientras que el cargo de senador fue ejercido por varios miembros de su familia: Jácome Vivaldo en 1577, Andrés Vivaldo en 1581, Juan Bautista Vivaldo en 1590 y Jerónimo Vivaldo en los años 1628, 1640 y 1646; por otro lado, la dignidad de gobernador y capitán de Chavaris la desempeñaron Jácome Vivaldo en 1565 y Lelia Vivaldo en 1600; el consulado de Génova en Tana fue ocupado en 1429 por Andreolo Vivaldi y, finalmente, Felipe Vivaldo actuó como capitán de la Armada Genovesa en 1423, Rivarola y Pineda, J. F. F.: Historia Chronológica y Genealógica, civil, politica, y militar de la Serenissima República de Génova, Madrid, Diego Martín Abad, 1929, p. 419.

$10 \quad$ Ibidem, p. 419.

11 Archivo Histórico Nacional (AHN), Órdenes Militares, Caballeros de Santiago, 1649, exp. P. 8991. 
nobleza. La alcurnia quedaría, de alguna manera, confirmada por el matrimonio de este último con María Francisca Canevaro, del linaje de los Canevaro y Justiniano, los cuales sí estaban registrados en dichos libros. Además, algunos miembros de esta casa obtuvieron hábitos en diferentes órdenes militares, lo que prueba, aún más si cabe, su cuna ${ }^{12}$. Otra de las razones que avalan la prosapia de esta familia se apoya en que algunos de sus miembros hicieron carrera en el seno de la Iglesia, llegando incluso a ocupar puestos destacados en ella, como Juan Francisco y Pedro Francisco Levanto y Vivaldo que ejercieron como capellanes de honor de su majestad; el segundo, además, ocuparía el obispado de Badajoz ${ }^{13}$. También, tenemos constancia del agradecimiento del cardenal Mazarino a Juan Vivaldo Monaldeschi por los servicios prestados en Nápoles, pero desconocemos desde qué cargo eclesiástico, ayuda que bien pudo realizarse cuando el cardenal ejerció como diplomático en Italia ${ }^{14}$.

Fuera como fuese, lo cierto es que las ocupaciones políticas, religiosas y su pertenencia a la nobleza no impidieron a los Vivaldo su dedicación a los negocios, es más, supuso una ventaja debido a que al estar al frente del poder y en un estatus superior disfrutaron de numerosas prerrogativas. Como empresa siguieron el modelo clásico de compañía genovesa en la que la matriz se hallaba en esa ciudad, saliendo al exterior algunos miembros para trabajar como factores de la misma y estableciendo sucursales en determinadas plazas europeas ${ }^{15}$. Los asuntos tramitados por esta casa financiera fueron de diversa índole, entre los más destacados podemos señalar la realización de asientos para la corona ${ }^{16}$. Efectuaron operaciones de capital y actuaron como agentes para otras compañías, así como para instituciones como el Consulado de Sevilla ${ }^{17}$. Las ganancias obtenidas con todos ellos las canalizaron en inversiones de beneficios religiosos, censos y rentas de todo tipo. La disponibilidad numeraria y el prestigio adquirido a lo largo de los años les supuso a los Vivaldo que la Iglesia depositara en ellos la tesorería de la Cámara Apostólica, la cual se ocupaba de percibir las rentas eclesiásticas generadas en los territorios españoles, lo que fomentó, aún más si cabe, la credibilidad de la compañía, además de asegurar otros muchos dividendos.

Las grandes posibilidades de negocios que presentaba la corte de la Monarquía Hispánica fueron razones suficientes para que se asentara esta familia en Madrid, por lo que siempre contó con uno o varios agentes. Sin embargo, el deceso consecutivo

$12 \quad$ AHN, Órdenes Militares, Caballeros de Santiago, exp. P. 8993, expedientillos P. 1128, años 1623 y 1626 ; y Biblioteca de la Real Academia de la Historia (BRAH), M-34, 50.761 (6), fol. 29.

13 BRAH, Colección Salazar y Castro, signatura (sig.) 31, 75.050 (225), carpeta 14; sig. 32, 76.608 (40), carpeta 3; sig. 18, 76.609 (41) carpeta 3 y 19.

14 BRAH, Colección Salazar y Castro, sig. A-114, fol. 93.

15 Álvarez Nogal, C.: "Las compañías bancarias genovesas en Madrid a comienzos del siglo XVII", Hispania, LXV/1, 219 (2005) pp. 67-90.

16 Juan Pedro Vivaldo financió a la Corona en 1573, siéndole abonadas las consignaciones a través de las rentas del almacén de la sal de Avilés. El último empréstito proporcionado a la Hacienda Real se produjo tras la sublevación catalana, aportando 15.000 reales de a ocho de plata, que le fueron devueltos a través de los Derechos del Sello. Archivo de la Real Chancillería de Valladolid (ARCHV), Pergaminos, caj. 0024.0005; y Archivo Histórico de Protocolos Notariales de Madrid (AHPNM), Protocolo (Prot.) 8355, fol. 712-712v, Prot. 9351, fols. 206-207v, 347-348r, Prot. 11447, fols. 261-262r, 729-729v y Prot. 11454, fols. 172-172v, 771-771v.

17 Son varios los autores que hacen referencia a esta familia, como Álvarez Nogal, C.: "Los banqueros de Felipe IV y los metales preciosos americanos (1621-1665)", Estudios de Historia Económica, 36, (1997), pp. 161 y 177; Vila Vilar, E.: Los Corzo y los Mañara: Tipos y Arquetipos del Mercader con Indias, Sevilla, Universidad de Sevilla, 2011, pp. 137 y 141; LAPEYre, H.: Una familia de mercaderes: Los Ruiz, Valladolid, Editorial Server-Cuesta, 2008, p. 232; Rubio, J. A.: "La Fundación del Banco de Ámsterdam (1609) y la Banca de Sevilla", Moneda y Crédito, (1948), pp. 19-20; y SAnz AYán, C.: Los banqueros de Carlos II, Valladolid, Universidad de Valladolid, 1988, p. 508 (tabla XXI). 
de varios de ellos entre 1649 y 1656 obligará al páter familias a realizar una serie de reajustes en la empresa, siendo comisionado Juan Bautista Cassani para ocupar la delegación madrileña, la cual se hallaba en manos de su primo Juan Francisco Pascua, quien durante dos años le introducirá en el círculo mercantil de la capital, después partirá para Roma, donde ejercerá un tiempo como correspondiente de la casa en dicha ciudad, para pasar después a Nápoles con el mismo cometido. Por lo tanto, será en 1658 cuando Juan Bautista Cassani tome definitivamente las riendas de la compañía, no abandonándolas hasta su muerte en 1704. Seguirá desempeñando las mismas actividades económicas, aunque pronto abandonó la financiación a la corona española, tal vez como consecuencia de las sucesivas suspensiones de pagos que se produjeron durante el reinado de Felipe IV, las cuales desanimaron a muchos hombres de negocios a seguir sufragando las arcas reales ${ }^{18}$. No obstante, esta renuncia se suplirá con empréstitos a otras altas instancias políticas con las que mantuvo un estrecho vínculo, especialmente con los miembros del Consejo de Italia, a los que adelantaba los honorarios que percibían en estos territorios, donde los correspondientes de Juan Bautista Cassani se ocupaban de hacerlos efectivos, actuando, también, de agente para personalidades que pretendían en la corte algún beneficio o merced real.

Para desempeñar actividades de esta magnitud los miembros de la familia debían ser preparados desde la más tierna infancia en las más relevantes instituciones de la época. De hecho, Juan Bautista Cassani y sus hermanos varones, Domingo María y Marcos, estudiarán en el Colegio Romano de los jesuitas, centro académico que formaba a los hijos de las élites allí establecidas, así como a otros muchos jóvenes extranjeros que acudían por su prestigio ${ }^{19}$. Una vez completada la instrucción entraban a formar parte de la empresa familiar, acudiendo allí donde fueran requeridos. Domingo María estuvo ejerciendo como agente en Nápoles hasta su posterior traslado a Flandes, donde contrajo nupcias con Teresa Torgard, con la que tuvo cinco hijos. Marcos estuvo trabajando en Roma, trasladándose a Madrid en 1667 para colaborar con Juan Bautista en la delegación de la corte, aunque en 1671 regresará definitivamente a Italia. La red de correspondientes podía ampliarse a través del matrimonio, por esta razón su hermana Francisca casará con Carlos Ghirlandari, un hombre de negocios romano, quien junto a su socio Francisco Barlettani actuarán de agentes en esa ciudad, de este enlace nacerían tres hijos que prolongarán en el tiempo esta casa. Por último, anotar que su otra hermana, Ana Teresa, no formará parte del entramado mercantil familiar al ingresar como religiosa en el Convento de Santa María del Trastévere de Roma.

Juan Bautista Cassani a su llegada a Madrid se instaló en la casa que fuera de su tío Pedro Vivaldo, que a su vez era la sede de la compañía, la cual estaba situada en la calle del Lobo, en el barrio de los italianos, conocido en la actualidad como el de las Letras ${ }^{20}$. No será hasta pasados siete años de su llegada cuando se desposará

18 Sólo nos consta que realizó dos asientos en 1662 y en 1666 en compañía de Juan Bautista Crota, siendo el primero de 525.000 reales de vellón y el segundo de 37.500 reales de vellón, destinados a las Arcas Reales. SANZ AyÁn, op. cit. (nota 15), pp. 334, 503 (tabla IV) y 508 (tabla XXI).

19 Para la formación intelectual de Juan Bautista Cassani véase Gómez OreÑA, M.: "La espiritualidad de un hombre de negocios genovés asentado en el Madrid del siglo XVII. Juan Bautista Cassani Vivaldo" [en línea] Revista Destiempos, Revista de Curiosidad Cultural, 44, abril-mayo 2015, www.destiempos.com/n44/ RevistaDestiempos44.pdf [Consulta: 4 de mayo de 2015].

20 La calle del Lobo es la actual Echegaray, que nace en la Carrera de San Jerónimo y concluye en la de Huertas, está atravesada por la del Prado y la de Manuel Fernández y González, véase APARISI LAPORTA, L. M.: “Toponimia Madrileña. Proceso evolutivo", Anales del Instituto de Estudios Madrileños, XLI, (2001), pp. 39-68. 
con Francisca Antonia Fernández de Valdés, una joven huérfana de catorce años, hija del abogado de los reales consejos, Miguel Fernández de Merodio, oriundo de Antequera, y de Francisca de Valdés ${ }^{21}$, descendiente del boticario madrileño Lope de Valdés $^{22}$. Del matrimonio de Juan Bautista Cassani y Francisca Fernández nacerán siete hijos, aunque sólo les sobrevivió uno, José Félix, quien no seguirá la trayectoria profesional del padre, lo cual, y a pesar de las primeras reticencias, no supondrá una frustración para sus progenitores, puesto que su decisión de entrar a formar parte de la comunidad jesuita madrileña les reportará gratas alegrías al ver la gran vocación y virtudes del joven, quien con los años se convertirá en una personalidad destacada de la intelectualidad de su época ${ }^{23}$.

\section{Antecedentes de la embajada en época de Juan Bautista Cassani}

La confederación suiza estaba formada por trece cantones a los que se fueron uniendo otros territorios ${ }^{24}$. A pesar de que se reunían en una Dieta a la que concurrían dos representantes por cada cantón para debatir los temas que afectaban a toda la coalición, conservaban una gran independencia, lo que les permitía mantener negociaciones con otros países de forma autónoma ${ }^{25}$. Por afinidad religiosa la corona española mantuvo relaciones con los Cantones Católicos, señalados en la documentación consultada como Esguízaros, que son los que ocupan nuestra investigación, y con los Grisones, donde se situaba la embajada española en la segunda mitad del siglo XVII, más concretamente en la ciudad de Coira. Desde este emplazamiento, cuando los intereses españoles estaban comprometidos en las dietas, el embajador español se desplaza al lugar de celebración de la misma, bien fuera a Lucerna, si sólo estaba compuesta por católicos, o a Berna, si la componían los Trece Cantones ${ }^{26}$. Por el contrario, la representación de esguízaros y grisones en la corte madrileña se

$21 \quad$ Francisca de Valdés estuvo casada en primeras nupcias con otro abogado de los reales consejos y dramaturgo de fama reconocida, Jerónimo de Villaizán, siendo uno de sus mayores admiradores el propio rey Felipe IV. Urzáiz Tortajada, H.: "Del entremesista-bufón al 'hijo del Boticario': perfiles del dramaturgo del Siglo de Oro”, Revista de Investigación Teatral, 9, (2002), pp. 9-26.

22 Archivo de la Parroquia de Santiago de Madrid, Libro de Matrimonios 4, año 1663, fol. 84, y Archivo de la Parroquia de San Sebastián de Madrid, Libro de Matrimonios, año 1664.

23 José Félix accedió a la cátedra de matemáticas del Colegio Imperial de Madrid con veintiocho años, realizando esta actividad a lo largo de más de treinta (1701-1732). Fue uno de los fundadores de la Real Academia Española, donde llegó a ser decano de la misma, consultor y visitador de librerías del Santo Oficio y escritor de obras de temática diversa: hagiografías, astronomía, historia y matemáticas. Para conocer más detalles de él podemos consultar Eguía Ruiz, C.: "El P. José Cassani cofundador de la Academia Española", Boletín de la Real Academia Española, 22, (1935), pp. 7-30; Del Rey Fajardo, J.: Biblioteca de los Escritores Jesuitas Neogranadinos, Bogotá, Universidad Javeriana, 2006 y Vernet Gines, J.: Historia de la ciencia española, Madrid, Instituto de España, 1975, p. 159.

24 Los Trece Cantones eran: Berna, Zúrich, Basilea, Glaris, Schaffhausen, Uri, Schwyz, Unterwalden, Zug, Lucerna, Friburgo, Soleure y Appenzell. Los cinco primeros eran protestantes, los seis restantes católicos y en los dos últimos convivían ambas religiones. A ellos se unieron otros territorios: la Abadía de San Gall, el obispado de Constanza, Valais, las Ligas Grisonas, la Valtelina y los condados de Chiavenna y Bormio. Afferden, F., Harrewijn, J., Peeters J., Verdussen C. y H.: Atlas Abreviado o Compendiosa Geographia, del Mundo Antiguo, y Nuevo, Amberes, Juan Duren, 1696, pp. 61-62.

25 Bolzern, op. cit. (nota 5), pp. 63-71.

26 En la Guerra de los Treinta años estuvieron destacados hasta cuatro plenipotenciarios: Antonio Biglia y Francisco Casati en Coira, capital de las Ligas Grises, Carlos Casati en Lucerna, cerca de los Cantones Católicos, y su adjunto, Enrique Crivelli, en Altdorf, cerca de los Cantones Centrales. A pesar de estas delegaciones se comisionó a Saavedra Fajardo en cuatro ocasiones durante los años 1639, 1641 y 1642 para tratar con las autoridades suizas. QuER I Boule, op. cit. (nota 4), p. 92. 
llevaba a cabo con diplomáticos distintos, en representación de los primeros estuvo Juan Bautista Cassani desde 1667 hasta 1704, mientras que los segundos enviaron a varias personas, una de ellas fue el abad Baldirone, quien a la vez de ejercer como residente de estos, actuó como agente de la Congregación del Estado de Milán ${ }^{27}$, cuyos intereses eran contrapuestos. Otro de los desplazados a Madrid fue Pablo Buol, quien cobró algunas partidas que se debían a sus superiores gracias a la colaboración de Juan Bautista Cassani.

Desde que Carlos V empleó al primer regimiento suizo en 1520 para defender los Países Bajos, hasta la firma del Tratado de Utrecht en 1715, los mercenarios suizos formaron parte de los ejércitos hispánicos en numerosas ocasiones. Fueron contratados para servir en Flandes, pero sobre todo para la defensa del Estado de Milán, a cuyas huestes se integraban, también, y a pesar de las reticencias que tenían para cruzar el $\operatorname{mar}^{28}$, combatieron en España en 1663 en la gran ofensiva que proyectó Felipe IV para recuperar Portugal, con el que se mantenía una guerra latente sustentada con escasos efectivos desde $1640^{29}$. La firma del Tratado de los Pirineos con Francia en 1659 permitirá detraer recursos militares de Flandes y Cataluña, para enviarles al frente de Extremadura ${ }^{30}$. La gran ofensiva que se pretendía realizar hacía necesario emplear nuevas levas, lo que supuso un gran esfuerzo fiscal, teniendo que colaborar todos los reinos y señoríos hispánicos, incluidas aquellas provincias que estaban exentas ${ }^{31}$.

El sacrificio económico se destinará, entre otras cuestiones, a contratar tropas en territorios foráneos, incluidos los Cantones Suizos, aunque previamente tuvieron que solventar las deudas contraídas por los servicios prestados con anterioridad en los ejércitos milaneses ${ }^{32}$. A pesar de que la hacienda real siempre tuvo voluntad para saldar estas deudas, no siempre dispuso del dinero necesario, lo que provocó serios problemas en determinados momentos. De hecho, los cantones, ante la falta del abono y respaldados por el oro francés, se apoderaron de territorios del Estado de Milán, del que dependían sus consignaciones: Bellinzona, Locarno, Lugano, Menaggio y sus comarcas, así como la Valtelina, que fue ocupada por los grisones ${ }^{33}$, forzando

27 Álvarez-Ossorio Alvariño, A.: La República de las parentelas. La corte de Madrid y el gobierno de Milán durante el reinado de Carlos II, tesis doctoral, Madrid, 1993, p. 53. Sobre la Congregación del Estado de Milán podemos consultar también MAFFI, D.: “Anatomía de una élite de poder. El gobierno de Milán en tiempos de Carlos II”, en García García B. J. y Álvarez-Ossorio Alvariño, A. (eds.): Visperas de Sucesión. Europa y la Monarquía de Carlos II, Madrid, Fundación Carlos de Amberes, 2015, pp. 159-179, y en concreto, pp. 173-178.

28 En la correspondencia epistolar de Juan Bautista Cassani se hace referencia al hecho de que no querían pasar la mar. BRAH, borrador de carta manuscrita de Juan Bautista Cassani para Alonso Carnero, 13 de febrero de 1688.

29 Valladares, R.: La Guerra Olvidada. Ciudad Rodrigo y su comarca durante la Restauración de Portugal (1640-1668), Salamanca, Centro de Estudios Mirobrigenses, 1998 y La Rebelión de Portugal 1640-1680. Guerra, conflicto y poderes en la Monarquía Hispánica, Valladolid, Junta de Castilla y León, 1998.

30 Sobre la reducción de las consignaciones del ejército catalán EsPINO LóPEZ, A.: "La financiación de la guerra en la Cataluña del Barroco, 1652-1679”, Tiempos Modernos, 27, (2013), pp. 8-10. Mientras que para la reducción de los Países Bajos, RodríGuez Hernández, op. cit. (nota 2), pp. 65-93.

31 SÁnchez Belén, J. A.: "La aportación de la provincia de Álava a la contienda hispano-portuguesa en los años finales del Reinado de Felipe IV (1663-1665)", Espacio, Tiempo y Forma, serie IV, H ${ }^{a}$ Moderna, 12 (1999), pp. 249-273.

32 Ribot García, L. A.: "Milán, Plaza de Armas de la Monarquía", Investigaciones históricas: Época moderna y contemporánea, 10, (1990), pp. 203-238. En este trabajo aparecen las muestras tomadas al ejército de Milán desde 1635 hasta 1699. La milicia se compone de hombres de diferentes nacionalidades, los que son señalados como suizos entendemos que se refieren a los esguízaros, porque a los grisones se les denomina como tal.

33 Sobre estos territorios en el siglo XVII, Borromeo, A. (ed.): La Valtelina crocevia dell'Europa: politica e religione nell'età della Guerra dei Trent'anni, Milán, G. Mondarino, y Sondrio, Fond. Credito Valtellinese, 1998; Ceschi, R. (ed.): Storia Della Svizzera italiana dal Cinquecento al Settecento, Bellinzona, Casagrande, 2000; Coolidge, W. A. B.: I Grigioni nella storia, Varese, Edizione Fondazione Monti, 2008; Storia dei 
con ello a Felipe IV a encomendar al presidente de la hacienda real que formase una junta para determinar cómo se les podía satisfacer ${ }^{34}$. Una vez designadas varias rentas en el Estado de Milán, éstas no fueron abonadas con la puntualidad deseada, por lo que se les gratificará con un juro sobre la media anata de mercedes de 4.400.000 reales de vellón de principal, que les reportarían una renta anual de 220.000 reales de vellón ${ }^{35}$, cantidad que compartirán con los grisones hasta 1666. Después de esta fecha, y debido al incremento de la deuda tras los servicios prestados por los dos regimientos que sirvieron en el frente de Extremadura, pasará íntegramente en cabeza de los esguízaros.

Una vez resuelto el problema de las retribuciones se negoció la contratación de los citados regimientos, cuya llegada a España fue prevista para $1663^{36}$. A la vanguardia de ellos se encontraban el coronel Carlos Jerónimo Cloos y el comendador Juan José de Beroldinghen ${ }^{37}$, mientras que en Madrid, y en calidad de embajador extraordinario, se situaba el hermano de este último, el coronel Carlos Conrado, encargado de ajustar y solventar todas las cuestiones previas a su llegada y, una vez en territorio hispánico, asistirles en todo lo que precisasen, pues aunque el abastecimiento corría a cargo de la corona, la vestimenta y el armamento lo sufragaban los cantones $^{38}$.

Para aprovisionar a las huestes esguízaras, el coronel Carlos Conrado de Beroldinghen precisó de grandes cantidades de numerario, del cual carecía en ese momento, lo que le obligó a acudir a los hombres de negocios de la corte, entre los cuales se encontraba Juan Bautista Cassani ${ }^{39}$. Los primeros acuerdos llevados a cabo entre ambos personajes se produjeron en enero de 1664, poco antes de partir el coronel

Grigiono, Coira y Bellizona, Casagrande, 2000, vol. II; y Wendland, A.: Passi alpini e salvezza delle anime: la Spagna, Milano e la lotta per la Valtellina, 1620-1641, Sondrio, L’Officina del Libro, 1999.

34 AHN, Estado, leg. 1929, memorial del 19 de enero de 1662; y AHPNM, Prot. 9351, fols. 335-337v.

35 Para la conversión de monedas hemos tomado como referente Collantes PÉrez-Arda E. y Merino Navarro, J. P.: "Alteraciones al sistema monetario de Castilla durante el reinado de Carlos II", Cuadernos de Investigación Histórica, 1 (1997), pp. 73-98.

36 Desconocemos la fecha exacta de su llegada, puesto que en los documentos consultados aparecen dos diferentes: 1663 y 1664, aunque nos inclinamos a pensar que fue en 1663 cuando Felipe IV ordenó que se agilizara el reclutamiento para participar a tiempo en la campaña de febrero de 1664, según señala RoDRíGUEz HERNÁNDEZ, A.J.: "Al servicio del rey. Reclutamiento y trasporte de soldados italianos a España para luchar en la Guerra de Portugal (1640-1668)", en MAFFI, D.: Tra Marte e Astrea. Giustizia e giurisdizione militare nell'Europa della prima etá moderna (secc. XVI-XVIII), Milán, Franco Angeli, 2012, p. 246.

37 Los Beroldinghen eran una familia de militares que estuvieron sirviendo en las huestes españolas desde 1520. En torno a ella se formó el partido pro español en los Cantones Católicos. Eran originarios de Altdorf, ciudad del cantón de Uri, pero pronto se transfirieron a Lugano y Mendrisio en el Cantón de Ticino, donde formaron parte de la élite política, alcanzando un gran prestigio, de hecho, son reconocidos como personajes ilustres. OLDELLI G. A.: Dizionario Storico-Ragionato delli uomini illustri del Canton Ticino, Lugano, Francesco Veladini e Comp., 1807, pp. 31-35. Podemos encontrar una mayor información en GómeZ OrEÑA, M.: La casa y negocio de Juan Bautista Cassani. Un financiero genovés en la España del siglo XVII, tesis doctoral, Universidad Nacional de Educación a Distancia, 2015.

38 La vestimenta no era un tema baladí, pues en el fragor de la lucha precisaban distinguir al enemigo, sobre todo cuando participaban varias naciones en el conflicto. Los uniformes eran de vivos colores y además llevaban alguna señal distintiva. En cuanto al armamento surgieron problemas con las armas de fuego, pues al no estar homologadas la munición que les servían no se adecuaba a todos los modelos. Véase PARKER, G.: "La Guerra Dinástica", en PArker, G. (ed.): Historia de la Guerra, Madrid, Ediciones Akal, 2010, pp. 156-161.

39 Regularmente el alistamiento de los efectivos militares se hacía independientemente de las fronteras cantonales, por lo que el comandante que dirigía el regimiento, que solía tener entre 1500 y 2000 hombres, era el responsable del sueldo y de la observancia de sus obligaciones. La conducción de los regimientos conllevaba unos desembolsos considerables, por lo que las grandes oligarquías militares debían disponer de grandes medios financieros para sostenerlos, pero no siempre se contaba con el numerario suficiente, por lo que acudían al crédito de los banqueros. Véase Nicolaus, B.: "I reggimenti svizzeri in servizio all'estero", La Rassegna d'Ischia, 1 (2006), p. 5. En el caso que nos ocupa el coronel de Beroldinghen actuaba en nombre de sus superiores. 
para la Helvética, siendo firmados dos documentos notariales, uno concerniente a un préstamo de 117.600 reales de vellón, y el otro, un adelanto económico de 13.000 reales de vellón, relativos al arrendamiento de la despensa y botillería que le pertenecían por ser embajador. Juan Bautista Cassani se ocupará de gestionar y percibir dicho arriendo, además será autorizado para cobrar de las arcas reales el juro de la media anata de mercedes ${ }^{40}$.

A pesar del gran dispositivo militar empleado contra Portugal, la derrota definitiva se producirá en 1667, lo que obligará al coronel Carlos Conrado de Beroldinghen a regresar a la corte madrileña para realizar las gestiones relativas al licenciamiento de las tropas esguízaras, las cuales habían quedado muy diezmadas, cayendo incluso en el campo de batalla el hermano de este último. También se ocupará de percibir todo lo que había recaudado Juan Bautista Cassani del juro, cuya cantidad no será suficiente para saldar las deudas que las tropas generaron ni para su posterior desplazamiento a la Helvética. Además, la hacienda real no pudo hacer frente en ese momento a todo el montante que supuso el despido de los dos regimientos ${ }^{41}$, viéndose forzada a aplazar una parte de lo adeudado y añadirlo al importe del principal del juro de la media anata, quedándose establecido, como ya hemos señalado, en las mismas condiciones que cuando lo compartían con los grisones. El resto, 420.000 reales de vellón, serían abonados, siguiendo las órdenes del presidente de hacienda, por Juan Bautista Lomelín y Granada, quien los haría efectivos a través de varias letras pagaderas en las ciudades de Génova o Milán, según dictaminase Juan Bautista Cassani ${ }^{42}$.

El retraso en el pago y la falta de liquidez obligará al coronel, en nombre de sus superiores, a solicitar a Juan Bautista Cassani un préstamo, quien lo concederá muy complacido, no sólo por los intereses devengados, sino porque quedaba como representante diplomático de los Cantones Católicos ${ }^{43}$. Asimismo, Carlos Conrado de Beroldinghen le comisionó para que en su nombre cobrase del erario español la merced que por vía de encomienda le concedió el rey por haber perdido a su hermano en el frente extremeño, cuyo principal ascendía a 96.000 reales de vellón, los cuales también estaban situados sobre el juro de la media anata de mercedes ${ }^{44}$. Por otro lado, el secretario de la embajada, Carlos Jerónimo Gnoqui ${ }^{45}$, también le apoderó para que cobrase del tesorero de las arcas de la hacienda real los 5.000 reales de vellón que le correspondían por ayuda de costas ${ }^{46}$. Por último, Juan Bautista Cassani liquidó el crédito de 84.000 reales de vellón que el coronel tenía contraído con Juan

$40 \quad$ AHPNM, Prot. 8357, fol. 484-484v y 485-485v.

41 AHN, Estado, leg. 1929, memorial del 6 de abril de 1676. Junto a estos dos regimientos de esguízaros acudió otro de grisones al mando del coronel Pedro Planta. Estos tampoco fueron liquidados tras el despido, por lo que en abril de 1667 el abad Antonio Baldirone, residente de los Grisones, solicitará que, a cuenta de lo que se les debía, se les concedieran dos plazas de cuestores con sus gajes y emolumentos, siendo una de ellas para el doctor del Colegio de Milán Francisco Pozzobenelli, hijo del marqués de dicho nombre, cuyos méritos al servicio de su majestad fueron notorios; la otra plaza sería para Cristóbal Columbo, "sujeto de toda aprobación". Estos dos cargos que habían sido denegados en 1665 fueron finalmente concedidos, puesto que de esta manera se reducía la deuda y se evitaba la represalia que pudieran tomar los grisones, como ya lo habían hecho tiempo atrás cuando se apoderaron de la Valtelina.

42 De esta entrega tenemos constancia por dos fuente distintas: AHPNM, Prot. 9351, fols. 424-425v; y AHN, Estado, leg. 1929, billete del 4 de junio de 1667 del conde de Villaumbrosa.

43 AHPNM, Prot. 9351, fols. 339-340v.

44 AHPNM, Prot. 9351, fols. 345-346v.

45 Carlos Jerónimo Gnoqui posteriormente ejercerá como sargento de una compañía franca de alemanes, AHN, Estado, leg. 1876, años 1622-1703.

46 AHPNM, Prot. 11447, fol. 15-15v. 
de la $\mathrm{Hoz}^{47}$.

La suma final de todos los préstamos ascendió a 2.100.000 reales de vellón, que les fue imposible saldar a los esguízaros en el plazo establecido, por lo que se vieron en la necesidad de traspasarle casi la totalidad del juro de la media anata de mercedes, que le reportaría a Juan Bautista Cassani una renta anual de 420.000 reales de vellón. Tal decisión fue acordada el 8 de abril de 1680. Suponía una cesión perpetua para él y sus sucesores, disfrutando de los mismos privilegios, facultades y prerrogativas que les había concedido la corona española en diciembre de 1667. Asimismo, en el documento de trasmisión se comprometieron a que si por las estrecheces y necesidades que siempre apretaba a la hacienda real se le dejara de pagar el total, el quince o veinte por ciento de la renta, como era habitual, se comprometerían a sacar un despacho de su majestad para que el juro quedase siempre excluido de los descuentos y, si fuera necesario, enviarían un embajador extraordinario a Milán o a la corte, siempre que lo solicitase Juan Bautista Cassani o sus sucesores, aunque precisaron que su coste correría a cargo del demandante. Por otro lado, añadieron que el pacto quedaría sin valor si le satisficieran el importe total de la deuda ${ }^{48}$.

La buena disposición de las autoridades esguízaras hacia su embajador cambiará en 1684 cuando éste cayó en bancarrota, precisamente por no haber percibido del tesorero de la media anata de mercedes los beneficios del juro, así como otras rentas que le adeudaban, lo que le privó de la liquidez necesaria para satisfacer a sus acreedores, entre los que se encontraban sus superiores, quienes le demandaban la parte que les correspondía del citado juro, a pesar de tener constancia de no percibirlo, ya que en otra ocasión que quebró otro tesorero de la media anata asumió el propio Juan Bautista Cassani la deuda, entrando él en el concurso de acreedores en lugar de ellos ${ }^{49}$. No conformes con exigirle las cantidades adeudadas algunos senadores esguízaros quisieron despojarle de su cargo de embajador. Ante este hecho, Juan Bautista Cassani luchó para seguir en su puesto por ser en esa situación de quiebra cuando más necesitaba la plaza. Es más, ofreció su empleo a aquél que le entregase todo el dinero que había desembolsado durante su embajada, aun así, aunque hubo varios pretendientes, al ser un montante tan elevado nadie quiso acceder a ella, quedando en su ministerio, pero no sin antes sufrir la incertidumbre durante más de un año ${ }^{50}$

\section{La legación diplomática}

Las principales delegaciones diplomáticas solían estar encabezadas por altos miembros de la nobleza, pero no sólo ellos ostentaron estos cargos, también hubo personas de origen hidalgo, siendo uno de los personajes más destacado el ya citado Saavedra Fajardo, que estuvo comisionado en diferentes territorios de Italia y del Imperio $^{51}$. Asimismo, religiosos, artistas y hombres de negocios podían desempeñar este puesto. Los pequeños estados solían tener preferencias por estos últimos para

\footnotetext{
AHPNM, Prot. 9351, fols. 414-415v y 631-631v; y BRAH, leg. 20, sig. 9/7234.

Copia del documento original, Madrid, 6 de marzo de 1732, BRAH, Jesuitas, leg. 20, sig. 9/7234.

Carta de Juan Bautista al conde Casati, 7 de febrero de 1687, BRAH, sig. 9/3642R.

BRAH, 9/3642.

51 Ochon Brun, M. A.: Historia de la Diplomacia Española. La Edad Barroca, Madrid, Biblioteca Diplomática Española, Ministerio de Asuntos Exteriores, 2006, vol. VIII, p. 14.
} 
que les representasen en las naciones aliadas, principalmente porque la imperiosa necesidad de beneficios les capacitaba para maniobrar entre las autoridades donde se asentaban. La creación de los consulados en la Edad Media les dotó de una destreza significativa en las relaciones internacionales ${ }^{52}$. Razón por la cual en algunos casos, como el que nos ocupa, la delegación diplomática quedaba en una persona foránea del territorio representado. Al mismo tiempo, los comerciantes estaban interesados en desempeñar este puesto, no sólo por los honorarios percibidos, sino también, porque aprovechaban la coyuntura que les brindaban las estructuras y las prerrogativas de inmunidad de las embajadas, lo que se traducía en un incremento mayor de sus rendimientos ${ }^{53}$. Además, las gestiones realizadas para sus superiores en numerosas ocasiones representaban unas plusvalías adicionales, estando asociadas a cuantiosos desembolsos entregados para comprar voluntades, sirva de ejemplo lo acontecido en el año 1676 cuando la corona española quiso que se redujeran las pensiones que tenían asignadas los Cantones Católicos, para que admitieran esa rebaja se repartieron con todo secreto, entre los tres embajadores esguízaros que se desplazaron a Milán, importantes sumas y mercedes ${ }^{54}$.

Cuando el coronel Carlos Conrado de Beroldinghen eligió en nombre de sus superiores a Juan Bautista Cassani para que los representase tuvo en cuenta no sólo la disponibilidad de numerario y la buena sintonía que demostró tener con las autoridades del Consejo de Italia y del Estado de Milán, también la ostentación desplegada en su vida cotidiana, lo que daría suntuosidad a la embajada. Aun así, según consta en varias escrituras, los gastos en opulencia los incrementará de forma considerable. De hecho, su mayordomo y administrador, Juan Bautista Ruxero, empleó entre el 4 de junio de 1663 y el 30 de agosto de 1667 un total de 265.758 reales de plata, lo que hacía una media mensual de 5.211 reales de plata; mientras que estando ya como representante diplomático gastó desde el 1 de diciembre de 1668 hasta el 30 de septiembre de 1670 un total de 180.086 reales de plata, es decir, 8.186 reales de media mensual, lo que representa un $57 \%$ más que la anterior ${ }^{55}$.

La fastuosidad afectaría también a la vivienda, la cual, como ya hemos señalado, perteneció a su tío Pedro María Vivaldo, quien la adquirió en 1649, pasando después a su hermano y a un hijo de éste, Juan Vivaldo, quien se la venderá a Juan Bautista Cassani en 1667 por 3.300 reales de plata, un precio simbólico, puesto que sólo la

52 Sobre los comerciantes-embajadores, véase CARrió-InvernizzI, D. (dir.): Embajadores Culturales. Transferencias y lealtades de la diplomacia española, Madrid, Uned, 2016; Aglietti, M., Herrero SÁnchez, M. y Zamora Rodríguez, F. (eds.): Los cónsules de extranjeros en la Edad Moderna y a principios de la Edad Contemporánea, Madrid, Doce Calles, 2013. Sabbatini, R., y Volpini, P. (eds.): Sulla diplomacia in etá moderna. Politica, economia, religione, Milano, Franco Angeli, 2011, pp. 19-34; Anderson, M.S.: The Rise of Modern Diplomacy 1450-1919, London, Longman, 1993; Levine, M.: Agents of Empire: Spanish Ambassadors in Sixteenth-Century Italy, Ithaca, Cornell University Press, 2005. Ben Yessef Garfia, Y.: "Bautista Serra, un agente genovés en la corte de Felipe III: lo particular y lo público en la negociación política”, Hispania, 245, 2013, pp. ñ 647-672.

53 Uno de los privilegios que les reportaban importantes beneficios eran las franquicias, concesiones ofrecidas por la Corona a los diplomáticos y a determinados miembros de la alta sociedad. Esta prerrogativa consistía en la provisión de alimentos de primera necesidad, los cuales estaban exentos del pago de impuestos, permitiendo con ello la especulación al acaparar los productos y desabastecer el mercado, lo cual provocaba una subida muy elevada de los precios. Estos abusos, a pesar de las prohibiciones y ordenanzas que la administración dictó, se siguieron cometiendo hasta la total desaparición de las franquicias. Sobre éstas véase LóPEz GARcía, J. M. (dir.): El Impacto de la Corte en Castilla. Madrid y su territorio en época moderna, Madrid, Siglo XXI, 1998; y OCHOA BRun, op. cit. (nota 49), pp. 255-263.

54 Papel del 17 de marzo de 1676, AHN, Estado, leg. 1929.

55 AHPNM, Prot. 11447, fol. 857-859v. 
gravaron con el censo al que estaba sujeta ${ }^{56}$. Se ubicaba en una zona muy estratégica de Madrid, en la citada calle del Lobo, semiesquina a la Carrera de San Jerónimo, vía neurálgica que comunicaba el Alcázar con el Palacio del Buen Retiro, así se explica que estuvieran allí asentados los grandes banqueros reales. El edificio requería una adaptación al nuevo estatus y a las nuevas necesidades de representación, por lo cual invirtió en él 770.000 reales de plata ${ }^{57}$. Constaba de seis alturas, incluidas la cueva, el sótano y el desván; disponía de dos entradas independientes, lo que le permitió alquilar una parte de él cuando su situación económica se vio afectada por la bancarrota. Será precisamente un representante diplomático, el conde Wenzel Ferdinand Popel de Lobkowicz ${ }^{58}$, embajador del emperador entre 1690 y 1697, el que la ocupe, así lo señala Juan Bautista Cassani en su correspondencia epistolar ${ }^{59}$.

De ciertas mejoras tenemos constancia por documentos notariales realizados con varios maestros de obras, a los que encargó, entre otros cometidos, losar con piedra berroqueña el zaguán y el patio. En este último lugar ubicará una columna del mismo material, cuyo pedestal basa y capitel serían labrados y colocados sobre una losa de un metro cuadrado, alcanzando el conjunto una altura de cinco metros y siendo su coste de 1.000 reales de vellón ${ }^{60}$, lo que nos revela la sensibilidad artística de este personaje, reflejada asimismo en la infinidad de muebles y enseres de gran riqueza que poseía, como quedó registrado en el inventario realizado tras su muerte ${ }^{61}$. La mayoría de ellos estaban realizados en maderas nobles (nogal, caoba, ébano, palo santo), a los que no les faltaban las incrustaciones de marfil, plata, nácar e incluso de otras maderas preciosas. Aparte del mobiliario habitual de una vivienda -camas, sillas, armarios, cofres, aparadores y mesas...- proliferaron, sobre todo, los bufetes y escritorios, muchos de ellos utilizados en la oficina de su casa comercial, ubicada en la parte baja del edificio. La belleza ornamental no quedó sólo patente en el mobiliario, igualmente en los objetos decorativos, siendo muchos de ellos de plata. Si bien, la debilidad de este personaje fue la pintura, de la que poseía una importante colección, incluso mantuvo estrechos contactos con algunos artistas destacados de la época, como Andrés Smidt y Dionisio Mantuano, a los que confió la decoración de algunas salas del palacete que poseía en las afueras de Madrid, en una finca conocida como la Casa-huerta o Casa-puerta ${ }^{62}$, no descartando que también realizasen alguna obra en el inmueble de la calle del Lobo.

Al desembolso cuantioso de la reforma habría que sumar el mantenimiento de una vivienda de estas características, la cual precisaba de numerosos criados, además del personal adscrito a las labores específicas de la embajada, que Juan Bautista Cassani cubrirá con los mismos asistentes de su casa de negocios. De igual forma, se hacía necesaria la dotación de vehículos que personificasen su distinción diplomática. Dispuso de diversos modelos: estufas, carrocines, sillas de manos y forlones. Estos últimos le servirán para desplazarse a palacio a cumplimentar a los reyes en

\footnotetext{
AHPNM, Prot. 7925, fols. 542-546r; y AHN, Delegación de Hacienda, Libro 8, fols. 255-257v.

Carta de Juan Bautista Cassani al conde Casati, septiembre de 1690, BRAH, sig. 9/3642R.

58 Sobre Wenzel Ferdinand Popel de Lobkowicz véase Buriánková, M.: "La nobleza en servicios diplomáticos después del año 1648”, en Labrador Arroyo, F. (ed.): II Encuentro de Jóvenes Investigadores de Historia Moderna. Líneas Recientes de Investigación en Historia Moderna, Madrid, Ediciones Cinca, 2015, pp. 401-409.

59 Carta de Juan Bautista Cassani al coronel de Beroldinghen, 12 de septiembre de 1690, BRAH, sig. 9/3625.

60 AHPNM, Prot. 11447, fols. 26-26v; 50-50v; 75-76v; 372-372r, y 439-439v.

61 BRAH, leg., sig. 9/723426, 20 de octubre de 1704.

62 García Cueto, D.: Relaciones artísticas entre España y Boloña durante el siglo XVII, tesis doctoral, Universidad de Granada, 2005, p. 351.
} 
las ocasiones señaladas para tal fin, cuya riqueza decorativa queda palpable en la descripción que de ellos se hace en el inventario realizado tras su fallecimiento. La caja de uno de los dos que poseía fue realizada con tableros negros guarnecidos con tachuelas abollonadas, las compuertas eran de cordobán y el cabezal delantero fue tallado con dos figuras humanas negroides; el interior estaba recubierto con tela de alfombra, mientras que para las cortinas prefirieron un damasco azul y dorado. El habitáculo del otro forlón era de fino charol negro con sobrepuestos de follaje tallado, los pilares de las esquinas estaban elaborados de igual forma, en semejanza al cabezal y la cornisa del techo, éste además estaba encerado y guarnecido con una franja, las compuertas de cordobán fueron forradas en holandeta con doce pares de borlas de campanilla, los marcos de los cristales presentaban molduras de madera de diferentes tipos, estando guarnecidas con dos órdenes de tachuelas, lisas y doradas; los herrajes mazorcados y ochavados fueron dorados, las ruedas teñidas de negro y el interior fue decorado con tela de triple labrado y seis cortinas de damasco.

Los honorarios que le concedieron a Juan Bautista Cassani sus superiores para que les representase con la decencia debida ascendían a 42.000 reales de vellón al año. A esta cantidad había que añadir el beneficio obtenido por las franquicias que le concedía la corona por ser embajador, lo cual no cubrirá todos los dispendios realizados, según señala en la correspondencia epistolar ${ }^{63}$.

Aunque los beneficios aparentemente eran lesivos, la rentabilidad la obtendrá por otros medios, puesto que su cargo de embajador facilitaba que muchos de los negocios de su casa comercial se realizaran con mayor fortuna. Pese a ello, la quiebra le afectará de lleno, pero incluso en esta situación se aprovechará de su posición diplomática al serle concedido por el Consejo de Estado un juez conservador que velase por sus intereses frente a los acreedores.

\section{Las negociaciones diplomáticas}

Existían diferentes categorías de diplomáticos, el estatus más elevado era el de embajador, que podía tener el carácter ordinario o extraordinario, esta misma condición se les daba a los enviados, tras éstos se hallaban los residentes, ministros y agentes $^{64}$. Los diferentes títulos no afectaban a las labores que debían desarrollar como plenipotenciarios, si bien, cuando los asuntos revestían una importancia mayúscula -firma de tratados de paz, enlaces reales, funerales regios, peticiones y demandas, etc.- se remitía una embajada extraordinaria, independientemente de si la nación era más o menos poderosa. De hecho, el coronel Carlos Conrado de Beroldinghen gozará de esta distinción por venir a España a solventar todas las cuestiones concernientes al traslado y dotación de los regimientos que sirvieron en Portugal. También su hijo, capitán de la caballería extranjera en Milán, fue comisionado como tal en Madrid para dar la enhorabuena al rey Carlos II por el enlace matrimonial con María Luisa de Orleans.

Fuera de que ostentasen un rango u otro, mantener en la corte madrileña una legación suponía para los Cantones Católicos un objetivo fundamental dado que las relaciones con la monarquía española se realizaban a través del Estado de Milán. El

Carta de Juan Bautista Cassani al conde Casati, febrero de 1687, BRAH, sig. 9/3642R.

64 OCHOA Brun, op. cit. (nota 51), p. 198. 
gobernador era su interlocutor más cercano, pero muchas de las demandas que le presentaban no las atendía favorablemente, bien porque los medios disponibles eran escasos, bien porque consideraba que gozaban de demasiados privilegios en dicho estado. Por lo tanto, la comunicación directa con el Consejo de Italia, del que dependía el citado estado ${ }^{65}$, resultaba de vital importancia, lo que les obligaba a mantener un residente a su lado que notificara en todo momento sus intereses, que no eran otros que conseguir empleo para sus tropas dentro de los ejércitos españoles, ya que era su fuente principal de ingresos. El lucro no se ceñía sólo a los periodos de guerra, puesto que la pésima coyuntura económica que atravesaba la corona obligaba, como ya hemos señalado, a aplazar los pagos y asignarles determinadas rentas para que cobrasen todo lo adeudado, las cuales solían estar sujetas a la hacienda del Estado de Milán, que se verá forzada a abastecerles de granos y sal, a permitirles la libertad de contratación de mercancías, a disponer de licencias de armas, al establecimiento de escolares suizos en la Universidad de Pavía, al sustento de otros muchos jóvenes que se disciplinaban en el Colegio Helvético, además de otras muchas prebendas ${ }^{66}$. Así se explica cómo en periodos de dificultades económicas las autoridades civiles y militares mostrasen oposición al reclutamiento y al sostén de los destacamentos esguízaros. Cómo lo prueba lo acontecido en diciembre de 1699 cuando el gobernador de Milán príncipe de Vaudemont, ante la imposibilidad de poder abonar el sustento del regimiento por estar las rentas comprometidas hasta 1702, solicitó una moratoria a los acreedores pagando los respectivos intereses, pero exigió la salida inmediata de las tropas. Si no cumplían tal disposición amenazó con retirarles el pan de munición y el socorro, medidas que podían agravarse inexorablemente ${ }^{67}$

A pesar de lo mencionado, los privilegios de los Cantones Católicos fueron satisfechos de forma más constante durante la embajada de Juan Bautista Cassani, lo cual se produjo por las buenas relaciones que mantuvo con los miembros de los consejos, así como con los gobernadores y la élite política del Estado de Milán ${ }^{68}$. Sus deberes como ministro de los esguízaros eran básicamente de tres tipos: informar al monarca de todas las negociaciones debatidas en las dietas cantonales, asistir a los esguízaros residentes en la corte o con intereses en ella y ejercer la representación de sus superiores ante el rey en las ocasiones señaladas para ello, bien fuera en eventos familiares -cumpleaños, bautizos, casamientos defunciones-, fiestas significativas o cuando algún acontecimiento extraordinario requiriese el homenaje.

En cuanto a sus atribuciones de informante Juan Bautista Cassani estuvo siempre muy solícito con las autoridades españolas para dar puntual aviso de todo lo que sucedía en la Helvética. Dos objetivos fundamentales perseguía con ello: demostrar su valía como diplomático, con lo que además posibilitaba otras cuestiones mercantiles concernientes a su casa de negocios, y dar una preponderancia mayor a los territorios que representaba, lo cual facilitaba el pago de las pensiones que les adeudaba

$65 \quad$ El Consejo de Italia se ocupaba de todas las cuestiones que afectaban a los territorios de los virreinatos de Nápoles, Sicilia y el Estado de Milán. Estaba compuesto por un presidente, un número indeterminado de secretarios y oficiales mayores, así como de seis regentes, de los cuales tres eran de origen español y los otros tres de los territorios italianos que representaban. Cuando los asuntos a tratar afectaban al Estado de Milán se tomaba el parecer del gobernador, al que posteriormente se le trasmitía las decisiones adoptadas por el consejo. Escudero, J. A.: La Administración del Estado en la España Moderna, Valladolid, Junta de Castilla y León, 1999 , t. II, pp. 326-335.

${ }_{66}$ AHN, Estado, leg. 1926, 14 de septiembre de 1699

67 AHN, Estado, leg. 1629, 23 de diciembre de 1699.

68 Para las parentelas políticas del Estado de Milán véase Álvarez-Ossorio AlvariÑo, op. cit. (nota 27). 
la hacienda española e impulsaba nuevas contrataciones de efectivos militares. Sin embargo, obtener información conllevaba mantener una red de contactos dentro del país representado y en los territorios circunvecinos, para lo cual contó con el coronel de Beroldinghen, el conde Casati, el conde Carlos Borromeo, miembro de la élite política del Estado de Milán, y el conde Heinrich Franz de Mansfelt ${ }^{69}$, embajador del Emperador en la corte española, quien le notificaba las noticias más importantes acaecidas en el Imperio. Si a través de estos personajes conocía la política exterior de los territorios centroeuropeos, las autoridades españolas también le proporcionaban noticias de dentro y fuera de sus dominios, lo cual trasladaba, a su vez, a sus informantes, manteniendo de esta manera una vinculación permanente del sistema de comunicación.

Los prolegómenos de una guerra representaban la coyuntura perfecta para solicitar el cumplimiento de las demandas prescritas con anterioridad y desatendidas en el tiempo, así como para formular nuevas peticiones de contratación de efectivos militares. Esto propiciaba que hubiera una masiva entrega de memoriales notificando todo aquello que se debatía en las dietas. Finalizado el conflicto con Portugal, los escasos regimientos esguízaros partieron para sus tierras de procedencia, desconocemos si fueron ajustados para el nuevo enfrentamiento que se produjo contra Francia en la llamada Guerra de Devolución (1667-1668). En los documentos consultados no aparece otra recluta hasta 1674, tampoco hay ninguna referencia en las muestras tomadas al ejército de Milán, a los que solían incorporarse ${ }^{70}$. En este último año la alianza con Holanda arrastraría a la Monarquía Hispánica a una nueva guerra contra Luis XIV, siendo las tropas necesarias para el socorro del Condado de Borgoña, que desde que lo heredó Carlos I se constituyó en un baluarte muy querido para los reyes españoles. Hasta 1635 se mantuvo en relativa calma debido a la neutralidad en la contienda franco-española, la cual estaba avalada por los Cantones suizos, la Liga Hereditaria de 1511 y por el tratado con Francia de 1522. Luis XIII rompió dicha neutralidad conquistando el condado, pero fue posteriormente restituido a su legítimo dueño. En 1668 su hijo, con la escusa del derecho de devolución, volvió a apoderarse de él, aunque por el Tratado de Aquisgrán lo devuelve, si bien, la anexión definitiva en 1674 se le ratificará en 1678 con la paz de Nimega ${ }^{71}$.

La coyuntura en los Cantones Católicos no era muy favorable hacia la corona española a causa de las deudas que tenían contraídas con ellos, lo que conllevó que

69 El conde ejerció su ministerio en Madrid desde 1683-1690. Sobre la familia Mansfelt véase SÁNCHEZ BELÉN, J. A.: "Lealtades contrapuestas: la familia del conde de Mansfelt durante la sublevación de los Países Bajos en tiempos de Felipe II", en Pereira Iglesias, J. L., De Bernardo Ares, J. M. y González Beltrán, J. M. (coords.): V Reunión Cientifica Asociación Española de Historia Moderna, Asociación Española de Historia Moderna, vol. 1, 1999, pp. 341-348.

70 Ribot García, op. cit. (nota 18), pp. 224-225. En las tablas aportadas en este trabajo sobre las muestras realizadas al ejército de Milán no aparece ninguna incorporación de infantería suiza desde la Guerra de Portugal (1667) hasta el 16 de diciembre de 1674. Llama la atención que sólo en esta fecha fueran contratados 36 suizos, lo que a nuestro parecer pudiera deberse a que hubieran quedado incorporados después de un licenciamiento de regimientos, como sucedió en noviembre de 1699 cuando tras el despido de 1.600 hombres, y ante la falta de numerario para abonarles los servicios prestados, se adhirieron en compañías sueltas del ejército milanés 300 esguízaros. Aunque resulta incomprensible que no hubieran sido reconocidos en las muestras de años anteriores, sobre todo si nos atenemos al memorial que remitió Juan Bautista Cassani el 27 de noviembre de 1699, según consta en el AHN, Estado, leg. 1929.

71 BÉLY, L.: Les relations internationales en Europe XVIIe-XVIIIe siècles, París, Presses Universitaires de France, 1992, "La representación de la frontera en las diplomacias durante la época moderna", Manuscrits: Revista d'història moderna, 26, 2008, pp. 35-51; DuRnerin, J.: "Relaciones Históricas entre el Franco-Condado y España”, Boletín Aepe, 20, 1979, pp. 37-44. 
las negociaciones fueran muy laboriosas y controvertidas, no obstante, se concedieron efectivos militares. El problema surgió con el resto de la coalición cantonal, ya que el Cantón de Berna, que siempre estuvo muy unido a los franceses, ofreció en un principio dar paso a los regimientos esguízaros, sin embargo, poco después rehusó hacerlo debido a que el embajador galo pagó una pensión a dicho cantón, así como otras sumas de numerario al resto de los protestantes. La primera dieta general concluyó sin acuerdo al manifestar estos últimos que por motivo de la liga mantenida con Francia, desde muchos años atrás, no podían dar paso a tropas y gentes que fueran a combatir contra dicha nación. Las alegaciones esgrimidas por el representante español, el conde Alfonso Casati, por el coronel de Beroldinghen y los demás católicos partidarios de la facción española, asegurando que no pedían el paso para luchar contra los franceses, sino que simplemente era para la defensa de Borgoña, no lograron convencerlos. Si bien es cierto que el dinero repartido por el diplomático francés ganó no sólo los votos de los protestantes, sino que, también, un cantón católico sucumbió a sus favores. Era de vital importancia para el rey Cristianísimo que las armas del soberano Católico no le importunasen por el Condado de Borgoña, puesto que desde allí se podía llegar fácilmente al corazón de Francia. Las negociaciones resultaron laboriosas a consecuencia del poco numerario del que disponía el conde Alfonso Casati, tan sólo 1.000 escudos, los cuales únicamente le sirvieron para el desplazamiento a las dietas, por lo que no pudo repartir nada entre los afectos del partido español. Tampoco ayudaba a la causa que las 7.000 doblas que se remitieron desde España a Milán para pagar los regimientos que sirvieron en Portugal todavía no habían sido entregadas a los Cantones Católicos, a pesar de haber enviado estos varias legaciones a esta ciudad para cobrarlos.

Juan Bautista Cassani, aparte de informar de estas noticias a las autoridades del Consejo de Italia, intentó persuadirlas alegando que la mejor forma de inclinar a los senadores esguízaros del lado hispánico era obligando al gobernador de Milán a pagar una pensión de las que se les adeudaba, lo cual sería tenido muy en cuenta por sus superiores. Además, les hizo notar que los participantes en la siguiente dieta estarían divididos en tres facciones distintas: los que eran partidarios de la pacificación de la patria, los católicos y los protestantes. A estos últimos se les podría convencer alegando que sería muy contraproducente que Francia conquistase el Condado de Borgoña, puesto que su cercanía sería peligrosa. Por otro lado, intuía que los subsidios que pretendían obtener de Luis XIV no podían serles satisfechos debido a los problemas económicos por los que atravesaba. Estos argumentos esgrimidos, entendía Juan Bautista Cassani, serían suficientes para inclinar la balanza del lado español ${ }^{72}$.

Conocedores los cantones de las necesidades de efectivos militares por parte de las principales naciones europeas, solían explotar al máximo las oportunidades de una buena y rentable negociación. Sin embargo, en algunas ocasiones los objetivos fueron tan ambiciosos que al no cumplirse les resultó frustrante. En la correspondencia política de Juan Bautista Cassani queda patente este hecho. Será en el contexto de la Guerra de los Nueve Años cuando se realicen en esos territorios numerosas negociaciones. A las dietas acudieron los senadores suizos de los Trece Cantones, el enviado francés, Amelot de La Houssaye, y los representantes de las naciones firmantes de la Liga de Augsburgo: representando al emperador el conde Londone y el barón de Landerset; el delegado del rey Guillermo de Inglaterra será Monseñor Cox;

Memorial de 1674, Archivo General de Simancas (AGS), Estado, leg. 3385 (2), fol. 128. 
el de las Provincias Unidas, Monsieur Falconiere; y, por España, el conde Carlos Casati. Las tres pretensiones fundamentales que demandaban los plenipotenciarios de la Liga a los Cantones Católicos se centraban en evitar el cierre de los pasos alpinos por los que debían trasladar tropas, la retirada de los efectivos militares de las plazas francesas conquistadas después de 1663 y la contratación de regimientos. Para que las negociaciones fueran más fructíferas se planteó realizarlas teniendo en cuenta la confesionalidad de cada país, lo cual facilitaba el ajuste; de esta manera, Inglaterra y Holanda pactarían con los protestantes, mientras que España y el Emperador lo harían con los católicos. Ambos bandos aspiraban conseguir un número muy elevado de efectivos, especialmente los ingleses, quienes firmaron unas cláusulas tan desorbitadas que finalmente no pudieron ratificar. De los 8.000 efectivos que auguraban conceder los helvéticos sólo fueron requeridos 4.000, lo que, como ya hemos señalado, les defraudó sobremanera y más teniendo en cuenta que se les exigió la retirada de las tropas que estaban sirviendo en el ejército francés, con el perjuicio económico que esto les supuso ${ }^{73}$.

Juan Bautista Cassani dio cumplida información al Consejo de Italia de todas las negociaciones que se estaban realizando en la Helvética. Esta institución quedó muy agradecida por sus avisos, ya que era casi el único canal de comunicación que tenían de ese territorio debido a que el embajador español asignado en esas tierras estaba obligado a despachar con el gobernador del Estado de Milán, y éste, a consecuencia de los muchos asuntos que llevaba entre manos, sólo notificaba al consejo los sucesos más reseñables ${ }^{74}$.

Las gestiones diplomáticas realizadas por Juan Bautista Cassani en defensa y protección de los ciudadanos de los Cantones Católicos en la corte madrileña quedan patentes con la intervención realizada en 1689 a favor de Pedro Locher, de la casa Locher e hijos de San Gall, previa petición del abad y máxima autoridad de dicha ciudad, confederada con sus superiores. Su arbitraje consistió en conseguir que la Junta de Represalia, constituida en 1689 con motivo del nuevo enfrentamiento militar entre Francia y España ${ }^{75}$, desembargase 4.000 escudos de oro que el citado mercader había remitido a José Rubín, su correspondiente en Madrid, y que se los habían retenido por considerar que era francés. Juan Bautista Cassani entregó a Alonso Carnero, secretario del Consejo de Italia, la carta del abad y una nota en la cual explicaba que a este mismo ciudadano en 1684 la citada junta también le tomó por ciudadano francés y le requisaron efectivos en Nápoles, los cuales finalmente fueron declarados libres gracias a las actuaciones del conde de Melgar, a la sazón gobernador de Milán, quien a instancias de los cantones declaró ser cierto que era ciudadano de San Gall. En esta ocasión también acudieron al nuevo gobernador, el conde de Fuensalida, pero como se hallaba dirigiendo al ejército supusieron que no habría podido dar cuenta a su majestad de este asunto, por lo que Juan Bautista Cassani escribió el siguiente memorial:

\footnotetext{
73 En las cartas que escribe al coronel de Beroldinghen y al conde Casati, así como en varios memoriales, se hace referencia a estas negociaciones, véase BRAH, sig. 9/3625.

74 Carta de Juan Bautista Cassani al conde Casati, 26 de junio de 1687, BRAH, sig. 9/3642R.

75 Para la represalia de 1689 véase Alloza ApARICIO, A.: Europa en el mercado español. Mercaderes, represalias y contrabando en el siglo XVII, Salamanca, Junta de Castilla y León, 2006, pp. 212-220; para la represalia francesa en la Guerra de Devolución consúltese SÁnchez Belén, J. A. y Ramos MedinA, M. D.: "Los comerciantes franceses en Castilla y la Represalia de 1667”, Espacio, Tiempo y Forma. Serie IV, Ha Moderna, 7 (1994), pp. 287-318.
} 
Cunpliendo yo como Ministro de Monss[eñ] ${ }^{\text {or }}$ Abbad de S[an] Gallo, que hace un cuerpo con los Cantones Catolicos, mis amos, y con la fee q[ue] se me remite, aseguro q[ue] Antt[oni $]^{\circ}$ Locher y Hijos son verdaderam[en $]^{\text {te }}[\mathrm{e}]$ sguicaros y no françeses. Y siendo la intencion de S[u] M[agestad] de favorecer y honrrar a los [e]sguicaros, sus confederados, supp $[1 \mathrm{li}]^{\mathrm{co}}$, con todo rendimi[en $]^{\text {to }}$, se sirva mandar despachar su R[ea $]^{1}$ decreto alla Junta de Represallas, q[ue] no sean molestados ni ellos ni el d[ic]ho $\mathrm{D}^{\mathrm{n}}$ Joseph Rubi, su cor[r]espondiente, por esta causa, $\mathrm{q}[\mathrm{ue}]$ asi se deve esperar de su R[ea $]^{1}$ Clemencia ${ }^{76}$.

Este asunto debía realizarse antes de que la Junta de Represalias emitiese sentencia, ya que podría resultar desfavorable a los intereses de la Casa Locher y extenderse en el tiempo una nueva resolución. Por ello, el citado agente solicitó a Juan Bautista Cassani que realizase nuevas instancias ante dicho tribunal, lo que le obligó a enviar otro memorial a Alonso Carnero suplicándole que si aún no se hubiera tratado este asunto, se viese rápidamente ${ }^{77}$.

Todo parece indicar que los oficios no tuvieron el final deseado, ya que tuvo que emitir un salvoconducto para que Pedro Locher se trasladara a Madrid, posiblemente para negociar él mismo el desembargo de la mencionada suma de dinero ${ }^{78}$.

En cuanto a la representación diplomática conllevaba una serie de distinciones y preeminencias de unas naciones sobre otras. La precedencia en actos protocolarios era uno de ellos y originaba frecuentes enfrentamientos entre los plenipotenciarios acreditados. El conductor de embajadores era la persona encargada de recibirlos, acompañarlos y conducirlos ante el rey, además disponía todo lo relativo a la normativa empleada y aconsejaba en todo momento las actuaciones a seguir ${ }^{79}$. Por tanto, era a él a quien debían dirigirse para interponer una queja cuando creían que sus derechos habían sido ultrajados, como en cierta ocasión haría Juan Bautista Cassani, actuando en nombre de sus superiores.

La cuestión que originó tal discrepancia se produjo en Augusta (Augsburgo), ciudad que no distaba más de diecisiete leguas de los cantones, a donde había llegado la reina Mariana de Neoburgo en su azaroso viaje hacia España después de casarse por poderes con Carlos II. A la citada localidad se desplazaron las delegaciones diplomáticas de la Liga de Augsburgo que estaban negociando en los cantones. La disputa se produjo entre el representante de los holandeses y el de los cantones por la primacía de quién debía ser el primero en dar la enhorabuena a la reina por su matrimonio. Juan Bautista Cassani elevó una consulta a Carlos Francisco del Castillo, quien creemos desempeñaba el citado cargo de introductor de embajadores. En el memorial expuso que desde el año 1648 a los holandeses se les habían concedido preeminencias superiores a las que les correspondían y sus superiores no estaban dispuestos a ceder ante ellos. La primacía sobre ellos había quedado patente mucho tiempo atrás. Para avalarlo se retrotrajo al Concilio de Trento, cuya historia, escrita por el cardenal Sforza Pallavicino ${ }^{80}$, le esclarecería algunas cuestiones al respecto,

\footnotetext{
Carta de Juan Bautista Cassani a Alonso Carnero, 6 de diciembre de 1689, BRAH, sig. 9/3625. Ibidem, 20 de diciembre de 1689.

BRAH, sig. 9/3625, 24 de septiembre de 1690.

OCHOA BRUn, op. cit. (nota 51), vol. VIII, pp. 342-370.

80 El cardenal Sforza Pallavicino escribió la Storia del Concilio de Trento bajo el nombre de Pietro Soave Polano o Fra Paolo. Véase los problemas de prelación durante el Concilio en CaSADo Quintanilla, B.: "La cuestión de la precedencia España-Francia en la tercera asamblea del Concilio de Trento", Hispania Sacra, 76 (1984), pp. $195-214$.
} 
como la protagonizada por el embajador de Baviera, quien pretendió preceder a los esguízaros que ocupaban asiento al lado del representante de Venecia, con quien estaban igualados por ser ambos superiores a los diplomáticos que no representasen a "cabezas coronadas", sin embargo, por decreto el bávaro tuvo que situarse detrás. Por otro lado, argumentó Juan Bautista Cassani, que en la Santa Sede, "cabeza del mundo cristiano que daba y quitaba los títulos a todas las potencias del mundo católico", existían tres estancias de recibimiento a los embajadores. La primera y principal era la "Sala Regia", donde el papa recibía por jerarquía a los diplomáticos de las "cabezas coronadas"; la segunda, conocida como "Semiregia", acogía a los esguízaros, y la tercera, "la Ducal", a la que llegaban por su orden los delegados ducales. Por si estos razonamientos eran insuficientes, Juan Bautista Cassani añadió otros que confirmaban más si cabe la superioridad, como el de la estima y consideración que en Francia sentían por los cantones, lo cual podía constatarse leyendo a P. Matthieu ${ }^{81}$, historiador de Enrique IV, quien escribió que cuando fue ratificada la liga con esta nación se desplazaron a París cuarenta y dos embajadores, tres por cada cantón, resultando ser esta delegación muy solemne. Otro argumento fue que en Lucerna, cantón principal de la confederación católica, se hallaba destinado un nuncio papal, estando ese delegado inmediatamente detrás de los que representaban a las casas reales y por encima de la de los príncipes católicos del círculo del Rhin, que a pesar de estar constituidos por muchos arzobispados, electores y príncipes, sólo existía un nuncio para todos. También era cierto, que Saboya y Florencia contaban con representante papal, pero estas naciones estaban consideradas de una categoría inferior a la de los Cantones Católicos. Por último, añadió que el emperador, el rey de España y el de Francia mantenían siempre un enviado permanente ${ }^{82}$.

Desconocemos cual fue la respuesta que le remitió Carlos Francisco del Castillo a Juan Bautista Cassani, aunque es muy posible que no fuera de su agrado, dado que la situación de Holanda en el contexto europeo había cambiado sustancialmente desde los inicios del siglo XVII, puesto que en 1672 se constituyó como la primera potencia comercial y marítima, arrebatando a Portugal la primacía del comercio de las especies ${ }^{83}$. Esta transformación económica demandaba una posición acorde al lugar que ocupaba.

\section{Epílogo}

La ubicación geográfica de los Cantones Católicos, además de ser fuente de suministros de mercenarios, les permitirá mantener un doble juego en sus relaciones con España y Francia. Cuando por necesidades de guerra ambas naciones se vieron obligadas a contratar efectivos militares en la Helvética, las autoridades esguízaras explotaron al máximo la situación, la maquinaria diplomática entraba en acción, tanto en los cantones como en las cortes de ambos países. Los embajadores destacados en las dietas repartirán importantes cantidades de numerario entre los senadores para

${ }_{81}$ Se refiere a la obra Matthieu, P.: Histoire de France et des choses memorables, advenues aux provinces estrangeres durant sept annees de Paix du Roy de Henry IIII, Roy de France y de Navarre, París, Chez I. Mettayer Imprimeur du Roy, 1605, fols. 184r-195v.

82 Carta de Juan Bautista Cassani a Carlos Francisco del Castillo, 29 de octubre de 1689, BRAH, sig. 9/3625.

83 Para el comercio holandés véase SÁnChez BelÉN, J. A.: "El Comercio Holandés de las Especies en España en la Segunda Mitad del Siglo XVII”, Hispania, 236 (2010), pp. 633-660. 
inclinar la balanza a su favor, mientras que en Madrid Juan Bautista Cassani, este financiero genovés de exquisita formación, con una gran experiencia en los negocios y con importantes parentelas en torno a las élites políticas, será la pieza clave que actúe conjugando los intereses hispánicos y los de sus superiores para facilitar las capitulaciones.

No sólo en periodos bélicos Juan Bautista Cassani operó con eficacia en su ministerio, será en épocas de paz cuando su labor tendrá más transcendencia al no poder apelar a las necesidades perentorias de la guerra, puesto que después del licenciamiento de los regimientos y la imposibilidad de poder liquidar la deuda se les asignaba unas pensiones anuales que, generalmente, no se les satisfacía en el tiempo señalado, lo que ahogaba económicamente a algunos cantones, dado que era su única fuente de riqueza. Esta coyuntura le obligaba a remitir persistentemente memoriales al Consejo de Italia para que fuese satisfecha la deuda. $\mathrm{Su}$ insistencia se revelará eficaz, dado que durante su ministerio fueron los adeudos cubiertos más asiduamente que en épocas anteriores.

La magnífica actuación de Juan Bautista Cassani en el desempeño diplomático queda perfectamente confirmada en sus más de treinta y siete años de trayectoria profesional. Ni siquiera cuando su casa de negocios cayó en quiebra en 1684 le retiraron los cantones de su ministerio, a pesar de que hubo muchas voces discrepantes y personas interesadas en desempeñar su cargo, manteniéndose en él hasta su muerte en 1704, que será sustituido por otro hombre de negocios asentado en Madrid, Jácome Francisco Andriani. 